\title{
Private Practice in Jordan
}

Zeid AbuGhosh $\bowtie$

Soc Int Urol J.2021;2(6):345-346

DOI: https://doi:10.48083/AHOP2343

"Nothing prepares you for this!" This is what you will hear from every urologist working in the private sector in Jordan. So, why am I here?

When I finished my fellowship in Canada in 2010, there were no jobs available at the university or in the public sector hospitals, so the only options for those beginning their careers were to go abroad and work in a foreign country or to try their luck with private practice. For those of you who do not know what private practice means in this system, I will explain. Basically, you rent a space and become licensed to operate a urology clinic. Then, since physicians are prohibited by law from advertising, word-of-mouth recommendations bring patients to you (they may refer themselves), and if you are lucky, other physicians will refer their patients to your care.

You have the choice to admit your patients to any private hospital. Patients pay a fee for service, which is often covered by their private insurance, but is sometimes paid out of pocket. After surgery, although there are hospitalists to take care of the patients, the surgeon is responsible for more than the usual follow-up careincluding things like the insertion of a Foley catheter at 2:00 a.m. on a weekend. If you are not available at all times, the emergency room physician will automatically call another urologist next time.

Your patients also expect you to be available all the time: it is not unheard of for patients to call at midnight for advice or to interrupt a special occasion to book an appointment. Even if you have a good office assistant, all the logistics other than answering the phone are your job. For example, if you need to book an operation, you have to call the hospital to negotiate a suitable time and date, as well as to establish that they have the necessary equipment and related disposables. Most of the time, you then have to call a supplier for the device or the disposables, and you have to coordinate with everyone. Getting to know your essential clinic supplies and where to buy them is an art in itself. It takes time-and a lot of disappointment-to perfect that art and find the reliable suppliers.
Another thing is sub-specialization. I trained as a urologic oncologist, but I was faced with a market in which a urologist cannot afford not to do the "bread and butter" work. Therefore, any case that comes into the clinic is served, regardless of specialization. Furthermore, I do my own diagnostics too. Urodynamics, ultrasounds, and minor procedures like flexible cystoscopy, Foley catheter insertion, suprapubic catheter change, percutaneous tibial nerve stimulation and shock wave therapy and intravesical instillations-all are done by me in the clinic without any assistance.

So why do I keep on doing this? For one thing, it pays relatively well. You never get rich being a physician, but you and your family live a comfortable life. It has not been easy: the first year of my private practice generated just enough money to pay the rent and the office assistant. The income doubled in the second year, so there were some earnings to take home. Even so, to support myself and my family during the first 5 years in practice, I had to supplement my income with a salaried job from 8:00 a.m. to 2:00 p.m., working in my own clinic after 2:00 p.m.

Another good thing about private practice is that you are your own boss. Nobody can tell you when and where to work, although your workday is 12 to 16 hours, and you work 6 days a week. Hospitals look at the doctor as a respected client who brings them his patients' business. Some pamper you more with free services to attract you and your patients, and this makes your life easier. As my practice has expanded, I prefer to do all my outpatient and inpatient care at one hospital for convenience; however, when a patient has a lower budget, we will move to another, less expensive, hospital. What hospitals charge the patients depends on the level of care and prestige. Most of the time you know in advance what the costs will be, and you can tell the patient what to expect. In the rare event of a complication, however, everything changes, so if your patient is paying out of pocket, it is best to be cautious. 


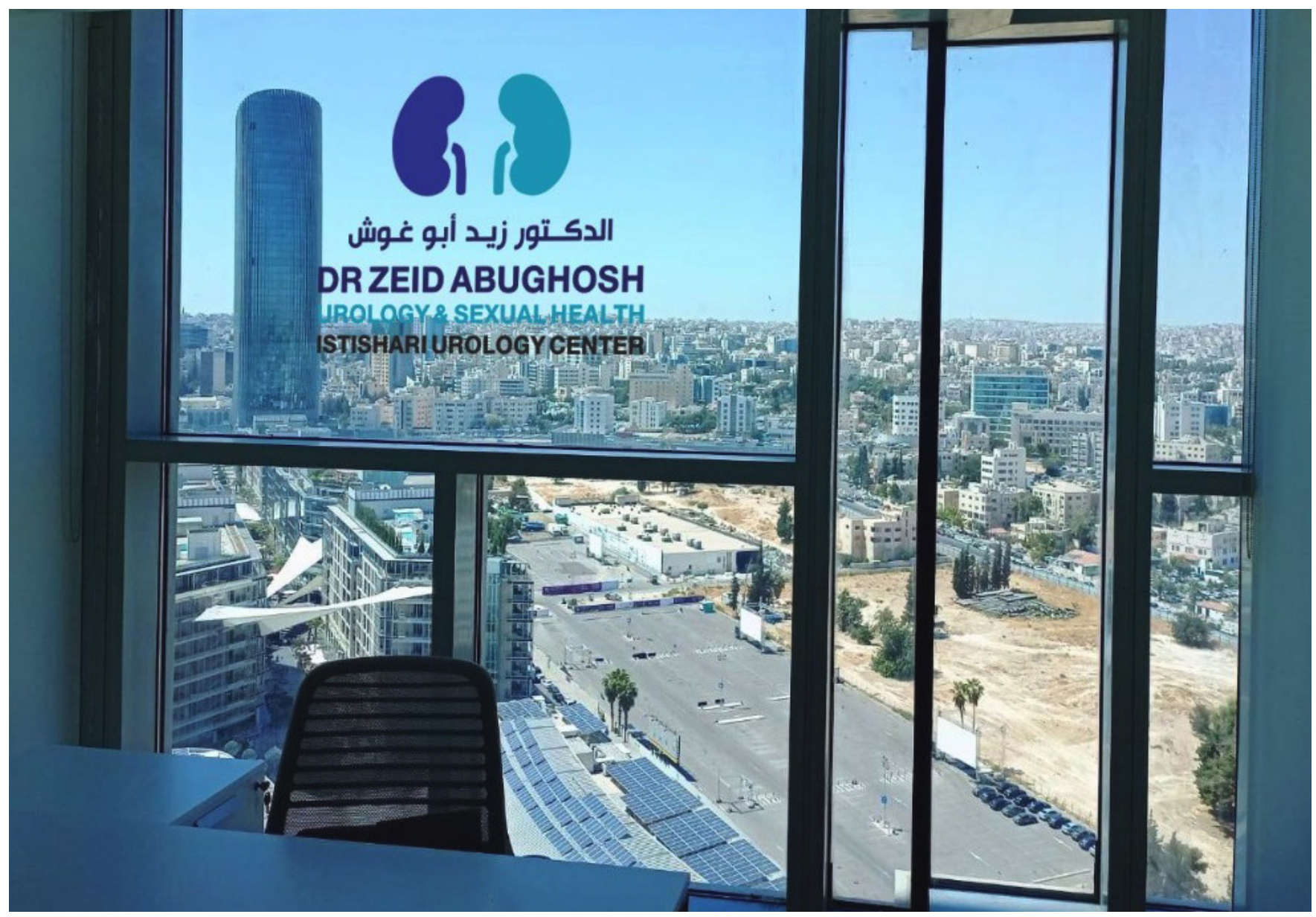

You can see that with all this disorganized organization, a little standardization would be a big improvement. To that end, I implemented cloud-based electronic health records to ensure patient data are secure and accessible, and I work with laboratories and radiology departments that have online access to the images and information. As collecting my patients' data is one of my responsibilities, this system makes my life easier; without it I would have to ask patients to bring in their results and reports.

Finally, to reach a broader population and to promote our services without breaking the rules on advertising, I established a TV show. Seven Doctors runs on a local Jordanian television channel and delivers medical tips for the general public in plain, non-technical language.
A few colleagues and I funded the development of the programme and learnt the tricks of trade, and for the past seven years, we have produced a one-hour weekly show that we sell (without profit) to the local TV station, which benefits from having a less expensive but much higher quality programme than they could have produced themselves. To increase the reach, we also turned to social media to offer advice and short tips to the public. All this, combined with word-of-mouth referrals based on honest scientific practice, has resulted in a fairly busy practice.

My next goal? To work to establish here the style of practice I saw in Canada, with group practice and specialization. 